
set./dez. 2018

\title{
UMA ANÁLISE DO EFEITO CARONA (FREE-RIDING), NUM AMBIENTE DE SHOPPING CENTER, EM PERÍODO PROMOCIONAL DE VENDAS
}

\author{
AN ANAL YSIS OF THE FREE-RIDING EFFECT, IN AN ENVIRONMENT OF \\ SHOPPING CENTRE, IN SALES PROMOTIONAL SEASON
}

\author{
FLAVIA ZOBOLI DALMACIO \\ Universidade de São Paulo. Endereço: Av. Bandeirantes, 3.900, Monte \\ Alegre | 14.040-905 / Ribeirão Preto/SP / Brasil. \\ (1) http://orcid.org/0000-0001-7776-1041 \\ E-mail: flaviazd@usp.br
}

\author{
LAISLLA OBARA IWAGASE \\ Universidade de São Paulo. Endereço: Av. Bandeirantes, 3.900, \\ Monte Alegre / 14.040-905 | Ribeirão Preto/SP / Brasil. \\ (1) $h$ ttp://orcid.org/0000-0003-3932-9607 \\ E-mail: laislla.iwagase@gmail.com
}

\section{RESUMO}

O objetivo geral deste estudo é analisar se o efeito carona (free-riding) ocorre num ambiente de shopping center, no período do Natal, em campanha promocional de vendas. O free-riding é definido como o efeito de atuação em que "um membro de um grupo obtém benefícios da membresia do grupo, porém não suporta um compartilhamento proporcional dos custos de prover tais benefícios" (Albanese \& Van Fleet, 1985, p. 244). Esse efeito é observado sob perspectiva da Teoria Econômica da Regulação, segundo a qual a regulação é instituída principalmente para proteção e benefício do público em geral ou de alguma grande subclasse do público (Stigler, 1971). Para mensurá-lo, foi utilizada uma proxy dos benefícios usufruídos por agentes não (proporcionalmente) contribuintes com a intervenção, bem como aplicaram-se questionários por meio de entrevistas com gerentes de lojas/quiosques dos shopping centers. A partir dos resultados obtidos foi possível constatar evidências do uso dos benefícios da regulação por lojas/quiosques não participantes. Portanto, conclui-se que o free-riding de fato ocorre num ambiente de shopping center, no período do Natal, em campanha promocional de vendas.

Palavras-chave: Teoria da Regulação. Free-riders. Shopping Center.

\begin{abstract}
The general aim of this paper is to analyze whether the free-riding tendency happens, in an environment of a shopping center, on Christmas season, in sales promotional. The free-riding is defined as an effect of actuation that "a member of a group obtains benefits from group membership but does not bear a proportional share of the costs of providing the benefits" (Albanese \& Van Fleet, 1985, p. 244). This effect is seen under the perspective of The Theory of Economic Regulation, according to which the regulation is instituted primarily for the protection and benefit of the public at large or some large subclass of the public (Stigler, 1971). To measure the free-riding, it was used a proxy of benefits enjoyed by agents who don't (proportionally) contributed with the intervention, well as the application of questionnaires by interviews with
\end{abstract}


store/kiosk managers in shopping centers. From the results obtained, it was possible to find out evidences for the use of regulation benefits by non-participants stores/kiosks. Therefore, it can be concluded that the free-riding in fact happens in an environment of a shopping center, on Christmas season, in sales promotional.

Keywords: Theory of Regulation. Free-riders. Shopping Center.

\section{INTRODUÇÃO}

Considere uma situação em que o Conselho de Administração de um condomínio exerça o papel de agente regulador e os condôminos, o papel de agentes regulados. As normas impostas por esse conselho implicarão em benefícios e custos aos agentes regulados, no entanto, nem sempre de forma proporcional, pois os condôminos que se mudarão para o condomínio após os aportes de capital decorrentes de alguma norma ${ }^{1}$ usufruirão dos mesmos benefícios, mas sem os respectivos custos.

Ou considere um contexto em que um professor de uma disciplina (agente regulador) exija de seus alunos (agentes regulados), mediante alguns requisitos (regras) e orientações, a elaboração de um trabalho em grupo para apresentação. Alunos descompromissados (freeriders $^{2}$ ), que não participam das reuniões para elaboração do trabalho, podem se beneficiar com a mesma nota que outros integrantes do grupo, sem terem feito proporcional ou algum esforço, tendo em vista que os alunos compromissados não possuem autoridade formal para punir ou excluir os free-riders e, por isso, acabam por consentir tais comportamentos dentro do grupo.

Essa relação entre agente regulador e agentes regulados foi estabelecida inicialmente pela Teoria Econômica da Regulação (Stigler, 1971), num contexto de Estado e grupos econômicos. Segundo essa teoria, a regulação é instituída principalmente para proteção e benefício do público em geral ou de alguma grande subclasse do público. Um grupo econômico pode buscar regulação ou esta simplesmente pode ser imposta a ele, sendo adquirida, moldada e operada primariamente em seu benefício (Stigler, 1971).

De acordo com Stigler (1971), o Estado é o agente regulador que tem o poder não compartilhado de compelir e seletivamente ajudar, por meio de alguns benefícios, ou prejudicar um vasto número de grupos econômicos. Stigler (1971) ainda destaca que o financiamento das atividades da empresa, tal como a regulação, leva ao problema usual do free-rider. De modo geral, o free-rider acaba usufruindo de determinado benefício, sem ter feito proporcional ou alguma contribuição (custo) para obter esse benefício.

O free-riding é definido como o efeito de atuação em que "um membro de um grupo obtém benefícios da membresia do grupo, porém não suporta um compartilhamento proporcional dos custos de prover tais benefícios" (Albanese \& Van Fleet, 1985, p. 244). As possibilidades de sucesso da intervenção (regulação) aumentam na medida em que o número de participantes potencialmente beneficiários é pequeno, mas também quando a posição destes no mercado é simétrica, uma vez que a assimetria pode incentivar o surgimento de free-riders (Downs, 1999).

Considerando esse efeito, a solicitação de suporte é complicada, pois os membros individuais não podem ser excluídos dos benefícios da regulação, mesmo que não tenham partilhado dos mesmos custos (Stigler, 1971). Segundo O'Neill (2010), o free-riding (efeito carona) ocorre quando uma pessoa extrai uma "externalidade positiva" das ações de terceiros, ou seja, adquire um benefício pelo qual ela não pagou. Além disso, "pessoas que nada têm a ver com a ação não podem ser impedidas de usufruir esses benefícios" (Stigler, 1971, p. 14).

Deste modo, é possível observar que a Teoria Econômica da Regulação (Stigler, 1971), apesar de desenvolvida para a indústria (setor), pode estar presente em distintos cenários, sempre que haja uma relação de agente regulador e agente regulado. Nesse contexto, sob uma perspectiva empírica, motivada por observação, busca-se nesta pesquisa analisar se alguns lojistas de centros comerciais e shopping centers que não participam de campanhas promocionais e festivas promovidas por seus administradores são beneficiados com aumento de vendas e/ou outros ganhos nesses períodos de campanhas.

\footnotetext{
${ }^{1}$ As normas são limitadas, pois não têm a capacidade de prever todas as situações e comportamentos possíveis. ${ }^{2}$ Caroneiros.
} 
A observação desses eventos induz alguns questionamentos: por que, apesar das regras (contratos entre as partes) que definem custos, benefícios e penalidades, não há unanimidade em termos de adesão às campanhas? Será que os lojistas que não participam, a princípio, obtêm benefícios econômicos e intangíveis (por exemplo, imagem) relacionados às campanhas? Esse comportamento poderia ser identificado como free-riding, motivado pelos contratos incompletos ${ }^{3}$ ? A não participação de alguns lojistas é decorrente de falhas na estrutura do regulamento e das normas de administração do shopping? Os lojistas não participantes percebem as falhas nas regras e agem oportunisticamente? Pragmaticamente, é possível impedir que as lojas não participantes das campanhas usufruam dos benefícios gerados? É possível limitar o acesso dos clientes às lojas não participantes? Os prêmios oferecidos nesses períodos promocionais não impactam o modelo decisório dos clientes, tornando a participação desvantajosa? Enfim, diante desses questionamentos, selecionou-se o ambiente de shopping center, em período de campanhas promocionais, a fim de verificar se ocorre o efeito free-riding e se evento pode ser explicado pelos pressupostos da Teoria Econômica da Regulação (Stigler, 1971).

Dias (2014, p. 43) acrescenta que "o conceito de free-riding aplicado ao varejo, (...), aborda a questão da não captura do uso de um recurso entre os participantes do mercado e, portanto, o mercado de tal recurso não produzirá um resultado ótimo". Portanto, permeando o ambiente empresarial, no qual se deseja a maximização de resultados com o mínimo de custos ou a ausência deles, procura-se com este trabalho responder o seguinte questionamento: o efeito free-riding pode ser verificado num ambiente de shopping center, no período do Natal, em campanha promocional de vendas?

Por meio deste trabalho, espera-se entender o modelo de regulação e seus impactos. Além disso, pretendeu-se extrapolar a aplicação da Teoria Econômica da Regulação, fundamentalmente voltada para a intervenção do Estado na economia, a fim de regular desequilíbrios do mercado e promover o desenvolvimento econômico em outros ambientes e arranjos econômicos, configurando novos agentes reguladores e novos grupos de interesses.

Ao verificar os efeitos da regulação no desempenho de lojas participantes e não participantes de campanha promocional de vendas, no período do Natal, as evidências encontradas poderão contribuir para a análise do comportamento dos agentes envolvidos sob esta perspectiva, além de incentivar o desenvolvimento de outros estudos, em cenários mais específicos.

\section{REFERENCIAL TEÓRICO}

\subsection{Regulação}

A regulação é um esquema instaurado com o intuito de prover potenciais usos de recursos e poderes para aprimorar a condição de grupos econômicos. A tarefa central da Teoria Econômica da Regulação é explicar quem receberá os benefícios ou fardos da regulação, que forma a regulação terá, e seus efeitos perante a alocação de recursos. Segundo a teoria de Stigler (1971), existem dois atores principais nessa relação: o Estado, agente regulador; e os grupos econômicos, agentes regulados.

O primeiro agente é um recurso potencial ou uma ameaça para todos os grupos econômicos, visto que detém a posse de um instrumento básico não compartilhado com os demais: o poder de coagir ou proibir. Tal poder lhe permite tomar decisões de cunho econômico sem o consentimento dos agentes regulados, podendo seletivamente ajudar ou prejudicar um vasto número de grupos (Stigler, 1971).

O segundo agente são os grupos econômicos que ativamente buscam a regulação ou sobre os quais esta é imposta. A princípio, a regulação é feita para proteção e benefício do maior público ou de algumas das maiores subclasses do público. Entre esses agentes são considerados indústrias (setores), ocupações e grupos de interesse (Stigler, 1971). Farhat (2007,

\footnotetext{
${ }^{3}$ Contratos incompletos "são fontes potenciais para o comportamento oportunista, implicando falhas de mercado e elevação dos custos de transação" (Silva \& Brito, 2013).
} 
p. 145) adota o seguinte conceito para grupos de interesse: "é todo grupo de pessoas físicas e/ou jurídicas, formal ou informalmente ligadas por determinados propósitos, interesses, aspirações ou direitos, divisíveis dos de outros membros ou segmentos de sua união".

Em sua teoria, Stigler (1971) fundamenta-se na intervenção do Estado na economia, no entanto, essa intervenção pode compor outros ambientes e arranjos econômicos, assim formando novos agentes reguladores e novos grupos de interesse. Como recurso potencial para os grupos, o agente regulador - qualquer que seja - pode oferecer benefícios sob as seguintes formas: subsídio, controle da entrada de novos concorrentes, fixação de preços e poder sobre itens substitutos e complementares. Tais benefícios podem ser observados no licenciamento de ocupações (e outros grupos); o uso da regulação nesse formato é uma barreira de entrada efetiva quando a prática ocupacional sem licenciamento constitui ofensa criminal (Stigler, 1971).

É de conhecimento geral que condutores automotivos devem possuir o registro da $\mathrm{CNH}$ (Carteira Nacional de Habilitação); médicos, do CRM (Conselho Regional de Medicina); advogados, da OAB (Ordem dos Advogados do Brasil); bem como contabilistas, do CRC (Conselho Regional de Contabilidade). Sem suas respectivas inscrições, não há permissão legal para exercer tais funções e, portanto, são inviáveis do ponto de vista ético-profissional e no âmbito legal.

Entende-se que a ofensa criminal pode implicar penalidades monetárias e não monetárias. Por exemplo, quando da ocorrência de ofensa conforme Detran (Departamento Estadual de Trânsito) - órgão regulador - ao respectivo estado, a penalidade pode não se limitar a multas, mas se estender à suspensão ou cassação da $\mathrm{CNH}$ de envolvidos e/ou chegar a um processo jurídico-legal.

Outras ocupações podem, ainda, exigir certificações específicas em vez de habilitações para atuar em suas atividades. Para esses casos, as certificações podem ser a porta ou barreira de entrada, como ocorre com profissionais do investimento. Segundo Leite (2010), no Brasil existem algumas certificações obrigatórias, de acordo com o cargo de cada profissional. Os principais são o CNPI (Certificado Nacional do Profissional do Investimento), o CPA-10 (Certificado Profissional Anbima - 10) e CPA-20 (Certificado Profissional Anbima - 20).

Por sua vez, Moreno (2014) afirma que estudantes que desejam obter bolsa de estudos no exterior geralmente também precisam de um certificado: o de proficiência na língua inglesa ou nativa do país de destino, sendo os mais comuns o TOEFL (Test of English as a Foreign Language), IELTS (International English Language Testing System) e CPE (Certificate of Proficiency in English).

Firmas e setores não ficam de fora. Bares, bem como outros empreendimentos, necessitam de alvarás para funcionar. Setores podem possuir exigências específicas. Por exemplo, a segurança alimentar é imprescindível para o ramo alimentício, de modo que as firmas devem estar certificadas na norma internacional ISO 22000 (International Organization for Standardization) - Sistema de Gestão da Segurança na Produção de Alimentos. Ressalta-se que a certificação pode ou não ser obrigatória e viabiliza outros ganhos, como: aumento de recebíveis, publicidade e propaganda e até mesmo intangíveis, como vantagem competitiva e ganho de reputação.

Em suma, a dificuldade da regulação é descobrir quando e por que um grupo é capaz de usar o órgão regulador para os seus próprios fins, ou é apontado pelo agente regulador a ser utilizado para fins alheios (Stigler, 1971).

\subsection{Limitações}

Conforme exemplificado, seria engano pensar que o licenciamento se restringe a um tipo de grupo - o de ocupações. Observa-se que a regulação pode assumir diferentes moldes: habilitações, certificações, alvarás, entre outros. Contudo, apesar dos benefícios, geralmente a regulação sofre algumas limitações. O conselho do grupo pode admitir estranhos em sua membresia, bem como pode haver uma oposição coesa sob a regulação (Stigler, 1971).

No caso do CPC (Comitê de Pronunciamentos Contábeis), autarquia formada pela união de esforços das entidades Abrasca, Apimec Nacional, Bovespa, Conselho Federal de Contabilidade, Fipecafi e Ibracon, é possível notar limitações. A membresia é composta por dois 
integrantes de cada entidade, em sua maioria contabilistas. A admissão de membros estranhos - não contabilistas - pode acentuar o conflito de interesses explicado pela Teoria de Agência ${ }^{4}$.

Ainda sobre o caso do CPC, a admissão de outras entidades ou especialistas convidados, tal como a Receita Federal, pode permitir que esse membro externo influencie significativamente na tomada de decisões, mesmo sem possuir poder votante. Assim, quando da divergência de interesses entre membros convidados e o grupo, pode haver oposição dos primeiros aos segundos visando impedir a regulação ou suas ações.

Outra limitação é a presença ou ausência de garantias processuais onerosas (custos administrativos). Adicionalmente, os efeitos da regulação sobre o grupo econômico podem ser onerosos ou não, implicando benefícios e/ou prejuízos para os agentes. Os regulamentos que prejudicam o público são os custos de alguma meta social ou, ocasionalmente, perversões da filosofia da regulamentação (Stigler, 1971).

Além disso, a probabilidade de sucesso da regulação está sujeita a condições de mercado: o equilíbrio entre a demanda e a oferta do grupo e sua elasticidade, ou seja, fatores fora do poder de controle total. Num grupo com integrantes numerosos, há um padrão de benefícios regressivos. Por outro lado, quando um grupo organiza esforços para obter uma regulação favorável e isso incorre em custos na solicitação de suporte, estes são maiores para um grupo difuso, se comparado a um concentrado (Stigler, 1971 e 1974).

Essas limitações são previsíveis e, portanto, devem todas entrar no cálculo da lucratividade da regulação do grupo. Stigler (1971) destaca, ainda, que a solicitação de suporte é complicada pelo problema de que estranhos (não membros) podem se apropriar dos benefícios da regulação, mesmo não compartilhando de seus custos.

\subsection{A Teoria do free-rider}

De acordo com Albanese e Van Fleet (1985, p. 244):

No discurso de todo dia, é frequentemente dito que "todos querem algo por nada". Claro que todas as pessoas em todos os lugares e a todo o momento não querem literalmente adquirir frutos sem suportar nenhum custo. Não obstante, geralmente é verdade que pessoas agindo racionalmente tentam minimizar seus custos frente aos benefícios recebidos.

À primeira vista, é aparente que a regulação ocorra apenas entre reguladores e regulados. Eis que então se nota a presença de um terceiro agente: o free-rider (o caroneiro).

De acordo com Mankiw (2006), o free-riding é "alguém que recebe o benefício de um bem, mas evita pagar por ele". Já para Gremaud (2003), o free-riding, além de pegar carona, é considerado como oportunista. Albanese e Van Fleet (1985, p. 244) afirmam que: "o termo 'freerider' refere-se a um membro de um grupo que obtém benefícios da membresia do grupo, porém não suporta um compartilhamento proporcional dos custos de prover tais benefícios". Stigler (1974, p. 360) complementa que "cheap rider" ("caroneiro barato") é um termo mais apurado para um membro de um grupo, pois receber benefícios da membresia tipicamente envolve algum custo.

Um flagrante exemplo do agente ocorre na simples coleta de frutos. Não há colheita sem que alguém tenha realizado o plantio. Slack, Chambers e Johnston (2002) afirmam que qualquer operação que produz bens ou serviços, ou um misto dos dois, faz isso por um processo de transformação baseado num modelo input-transformação-output. As sementes e outros insumos são os recursos de entrada (inputs), que passam pela transformação (transformation) e resultam nos frutos, ou seja, nas saídas (outputs).

Análogo ao modelo, os custos da regulação são nossos inputs para que o agente regulador realize transformações a fim de que outputs identificados como benefícios sejam gerados. Usualmente identificamos agentes (free-riders) que não contribuem da forma esperada com inputs, enquanto outros, sim.

\footnotetext{
${ }^{4}$ Essa teoria busca explicar a relação entre dois ou mais agentes que, embora comprometidos com a mesma atividade, possuem metas e atitudes individuais diferentes (Jensen \& Meckling, 1976).
} 
No Brasil, por exemplo, para os trabalhadores regulados por órgãos competentes há a exigência de contribuições para o bem comum - geralmente impostos federais trabalhistas. Enquanto isso, trabalhadores não regulados, tais como profissionais liberais e autônomos não declarados, não realizam essas mesmas contribuições, porém usufruem dos benefícios.

Em consonância com a popular frase "There's no such thing as a free lunch"5 ("Não existe almoço grátis"), a teoria do free-rider compartilha da ideia de que para tudo cujo acesso é limitado de alguma forma há um custo, mesmo que suportado por terceiros. Stigler (1974, p. 359) afirma que mesmo nesse nível de simplicidade, deve ser aparente que free-riders, assim como almoços, não podem ser totalmente grátis. Se a entidade não arca com o custo, alguém está arcando.

Olson (1965) explica como a teoria é uma tendência que opera para afetar a formação de grupos e a produtividade individual dentro deles: aponta sua utilidade para gestões teóricas e profissionais com implicações para projetos das unidades organizacionais; fornece um raciocínio para a reflexão sobre o efeito do tamanho do grupo em sua produtividade, em um alerta aos gestores de prováveis influências negativas nela. Essa teoria ajuda a explicar por que alguns grupos potencialmente úteis nunca se formam, e sugere contraforças úteis para a tendência.

Primeiramente, assume-se a essencial pressuposição de que indivíduos agem racionalmente. Para Albanese e Van Fleet (1985, p. 245), "racionalidade" significa que um indivíduo tem um conjunto ordenado e definido de preferências, interesses "egoístas"; quando livre para agir, então irá escolher comportamentos eficazes para alcançar essas preferências.

A preocupação central da teoria está no ator individual e em sua avaliação da rede de benefícios esperados ao contribuir com os interesses comuns do grupo em comparação com os benefícios do efeito free-riding (Stroebe \& Frey, 1982). Os membros do grupo podem decidir pelo free-riding, mesmo que todos estejam entusiasmados com o grupo e comprometidos com sua finalidade. Um consenso sobre a desejabilidade de benefícios de grupo não implica consenso em compartilhar os custos desses benefícios (Olson, 1965).

Por conseguinte, a junção de indivíduos para a formação de um grupo possui como característica crítica seu interesse em comum. Essa essência do grupo é o que fornece um benefício inseparável e generalizado. Olson (1965) apresenta o grupo por dois pontos: interesses em comum dos membros $\mathrm{x}$ interesses individuais dos membros. Embora o grupo tenha um interesse em comum, seus integrantes têm interesses individuais. A geração de conflito entre os interesses é explicada pela Teoria de Agência.

Tratando-se dos interesses e, naturalmente, dos benefícios, é válido diferenciá-los em bens públicos e privados. Antes de tudo, há de se definir a ideia de "bem": é qualquer coisa tangível ou intangível que satisfaça uma ou mais necessidades e/ou desejos de um indivíduo, podendo ser diferenciados por seus níveis de exclusividade (Albanese \& Van Fleet, 1985, p. 246).

Num grupo, um bem privado é algo pelo qual é exequível ou econômico excluir um ou mais membros, enquanto um bem público não admite essa exclusão. Um exemplo é a promoção do trabalho de um membro resultante de sua participação nas atividades do grupo. A promoção do trabalho satisfaz apenas aos interesses individuais e não aos coletivos, mesmo que a promoção fosse para mais de um membro. Por esse motivo, trata-se de um bem privado. Em contrapartida, no bem público tem-se o status compartilhado por todos os membros do grupo como resultado do alcance da meta coletiva. Nenhum membro do grupo pode ser excluído, embora nem todos possam compartilhar igualmente do status (Mckenzie \& Tullock, 1978).

$\mathrm{Na}$ prática, os bens fornecidos pelos grupos variam entre ambos os tipos. Pelos bens públicos satisfazerem os interesses comuns do grupo, são o foco principal da teoria. Na formação de um grupo desse tipo de bem, para uma repartição igual de benefícios, não é racional para um potencial membro suportar os custos de organização do grupo, pois o indivíduo receberá a mesma parcela relativa do bem público, assim como os que irão arcar com os custos. Será mais interessante deixar outra pessoa suportar esse custo. Alerta-se que se todos os potenciais membros agirem de tal forma, o grupo não será formado, e o bem público, interesse em comum do grupo, não será fornecido (Albanese \& Van Fleet, 1985).

\footnotetext{
${ }^{5}$ Provérbio popularizado pelo economista Milton Friedman. Em 1975, a frase foi título de seu livro, descrevendo o conceito de "custo de oportunidade" na literatura econômica (Friedman, 1975). Conhecido por um contexto do século XIX, o termo "free lunch" ("almoço grátis") tem sentido literal em que bares americanos ofereciam um "free lunch" (almoço grátis) desde que seus consumidores comprassem a bebida. A ideia é que é impossível conseguir algo por nada.
} 
Castro, Neves e Scare (2015, p. 386) acrescentam que, no caso de associações, os:

Associados estariam menos dispostos a assumir uma fração dos custos de um bem coletivo oferecido se perceberem que é possível tirar proveito de um bem coletivo, sem contribuir financeiramente com ele. Em outras palavras, o produtor não arca com os custos da associação, mas tira proveito (pega carona) nos bens coletivos produzidos por ela. Ao final, como produtores pagantes percebem que uns pagam e outros não, mas todos tiram proveito, existe a tendência clara de deixarem de contribuir também e, ao final, a associação deixará de existir, bem como seus bens coletivos oferecidos.

Uma vez que o grupo é formado, seu tamanho influencia decisões dos membros em contribuir para o bem público. São três os fatores que explicam a influência do tamanho do grupo no free-riding: visibilidade, perceptibilidade e parcela individual no bem (Albanese \& Van Fleet, 1985).

Primeiro, os membros de um grupo reduzido estão motivados a monitorar o free-riding, devido ao aumento significante do fardo de prover o bem público gerado pelos free-riders. Por se tratar de um grupo reduzido, seus membros podem facilmente notar se alguém está contribuindo para o bem público. Quanto mais isso acontecer, menos provável será que o membro opte pelo free-riding, pois se o fizer outros irão notar e, para não serem prejudicados, podem também se tornar free-riders. Se todos fizerem isso, o bem público não será fornecido. Portanto, para prevenir que isso ocorra, os membros farão suas contribuições notáveis para o bem público (Buchanan, 1965).

A dificuldade é que, com o aumento do grupo, a visibilidade da contribuição individual reduz, fazendo o free-riding mais provável. Adicionalmente, com o crescimento do grupo a motivação de monitorar o free-riding decresce, pois o impacto dessa prática é distribuído entre o grande número de membros do grupo (Albanese \& Van Fleet, 1985).

Segundo, em grupos reduzidos os membros estão aptos a perceber que suas contribuições individuais ao bem público irão fazer diferenças perceptíveis no montante total do bem fornecido e em cada parcela do bem dos membros. Contudo, conforme o grupo se amplia, é mais fácil para um membro concluir o oposto e, portanto, um indivíduo agindo racionalmente tenderá ao free-riding (Albanese \& Van Fleet, 1985).

Por fim, aponta-se que quanto menor o grupo, maior a parcela relativa do bem público que cada membro recebe. Esse último fator vai de encontro à limitação descrita anteriormente por Stigler (1971) de que, num grupo com integrantes numerosos, existe um padrão de benefícios regressivos. Em contrapartida, os custos para cada membro são maiores num grupo reduzido se comparado a um de maior volume (Albanese \& Van Fleet, 1985).

A respeito dos custos, um membro dominante do grupo pode estar disposto a suportar os custos totais de prover o bem. Olson (1965, p. 34) faz uma observação sobre grupos altamente reduzidos: "Quanto maior o interesse de um membro no bem público, maior a probabilidade de ele obter uma proporção do benefício total do bem tão significativa que ele contribuirá mesmo que tenha que arcar com todo o custo sozinho."

Em síntese, as possibilidades de sucesso da intervenção (regulação) aumentam na medida em que o número de participantes potencialmente beneficiários é pequeno, mas também quando a posição destes no mercado é simétrica, uma vez que a assimetria pode incentivar 0 surgimento de free-riders (Downs, 1999).

\subsubsection{O "problema" do free-rider}

Em 1965, as uniões trabalhistas estavam preocupadas com o free-rider, embora a prática tenha sido desconsiderada pelas principais teorias de movimento trabalhistas da época (Olson, 1965).

Nota-se atualmente que a ideia do free-rider é mais popular, ainda que de forma superficial. Em situações rotineiras, no ambiente de trabalho ou acadêmico, é possível identificar esses agentes, bem como nos ambientes que permeiam as organizações.

O problema do free-rider é reapresentado por Stigler (1974), mais precisamente como o problema do cheap rider. Stigler argumenta que, se tomada consciência de uma assimetria 
frequente ou típica de interesses de diferentes agentes num grupo, os incentivos individuais dos agentes para participar de um empreendimento conjunto são substanciais.

O’Neill (2010) complementa ao dizer que há aí um "problema" apenas quando se compara ao que poderia ter sido feito para impedir essa situação - uma suposta subprodução ineficiente do bem em questão. Em outras palavras, o problema é que, não fosse o caráter de não exclusividade do bem, as coisas poderiam ter sido ainda melhores.

\subsubsection{Resolvendo o "Problema" do Carona}

Segundo O'Neill (2010), sob certas condições haveria possibilidade de negociação com os usuários não contribuintes ("free-riders"), ao passo que o grupo econômico passaria a estar comprovadamente melhor - isto é, haveria um ganho de Pareto Eficiente ${ }^{6}$. Esse arranjo é uma decisão empreendedora, a qual não envolve coerção de qualquer lado envolvido. Contudo, evidencia-se que, caso não haja qualquer atividade voluntária por parte dos agentes, especialmente se arranjos propostos são recusados, é inexistente o potencial para ganhos eficientes no sentido de Pareto. Ademais, altos custos de transação podem impedi-lo, bem como outra razão qualquer.

Para Stigler (1974), numa ampla gama de situações, indivíduos falharão em participar de atividades coletivamente lucrativas na ausência de coerção ou incentivos individualmente apropriados. Por outro lado, O'Neill (2010) defende que existem consideráveis razões econômicas para não acolher "soluções" coercivas para qualquer suposto problema de ineficiência em decorrência de um "carona".

Posto que sob um arranjo empreendedor inexiste coerção, nele há garantia de que todas as partes usufruirão de ganhos ex ante ${ }^{7}$, enquanto sob um arranjo coercivo, não. Não há sentido presumir que o agente regulador desenvolverá arranjos com ganhos de Pareto Eficientes de melhor modo que os agentes contemplados com os frutos desses arranjos. Com base em argumentos da Teoria de Escolha Pública ${ }^{8}$ - sem mencionar nossas reais experiências com a oferta estatal de bens e serviços - são perceptíveis fortes motivos para acreditar que ao menos alguém sairá prejudicado (O’Neill, 2010).

Argumenta-se ainda que, se todos os agentes podem usufruir de ganhos, não há por que ter coerção e, portanto, espera-se uma solução empreendedora - isto é, não coerciva. Defensores da coerção como meio de solucionar o "problema" das externalidades positivas cometem um equívoco econômico básico ao desprezar as preferências dos agentes envolvidos, além de adotarem a política do "pagar forçadamente por bens e serviços não solicitados" como um ideal econômico. Para o autor, esse é de fato um dos ideais mais conspicuamente tirânicos da economia moderna (O’Neill, 2010).

\subsubsection{Revisão da literatura de pesquisas sobre free-riding}

Shin (2007), ao analisar como o comportamento free-riding no serviço de atendimento ao cliente afeta a competição, verificou que o free-riding de fato prejudica o varejista que oferece o serviço. Em contrapartida, quando os clientes são heterogêneos em termos de custos de oportunidade para fazer compras, o comportamento free-riding não só beneficia o varejista freeriding, mas também o varejista que fornece o serviço pré-venda.

De outro lado, são identificados também os consumidores free-riders, que "pegam carona" quando uma empresa não consegue cobrar por um serviço de informação pré-venda nem distinguir os consumidores oportunistas dos demais (Carlton \& Chevalier, 2001).

A literatura aponta que no "e-commerce" (ou "comércio eletrônico") existe uma tendência ao comportamento free-riding. É quando o consumidor busca informações sobre determinado produto num site mais completo e, após se informar, busca outros sites que ofereçam o mesmo produto com um preço mais baixo (Van Baal \& Dach, 2005; Spahn, 2013; Dias, 2014).

\footnotetext{
${ }^{6}$ Um ganho de Pareto Eficiente é aquele no qual pelo menos uma pessoa melhora sua situação e nenhuma outra fica pior em decorrência disso (O’Neill, 2010).

${ }^{7} \mathrm{Em}$ economia, o termo indica o que os agentes econômicos desejam ou esperam fazer (Simonsen \& Cysne, 2009).

${ }^{8}$ Ramo da teoria econômica em que conceitos da economia são aplicados à política e aos serviços públicos. Com a ideia de que "pessoas são pessoas" - sujeitas às mesmas motivações tanto na vida pública quanto na vida privada -, a escolha pública trata os políticos (reguladores) como agentes humanos que priorizam a satisfação do seu autointeresse em lugar do bem comum (Tullock, Seldon \& Brady, 2002).
} 
Ceribeli e Conte (2016) constataram alguns fatores que motivam a adoção do comércio eletrônico e influenciam diretamente a adoção do comportamento free-riding, dentre eles: (1) possibilidade de preços mais baixos nas compras realizadas pela Internet; (2) conveniência nas compras efetuadas online; (3) baixo risco do e-commerce; e (4) pré-disposição em buscar mais informações prévias em redes sociais.

No varejo tradicional (lojas físicas), o comportamento free-riding ocorre quando um potencial comprador avalia um produto fisicamente e coleta informações relevantes sobre ele e sua aplicabilidade, mas realiza a compra em outra loja física ou em site que ofereça alguma vantagem, como preços e condições de pagamento (Bakos, 2001).

\section{METODOLOGIA}

\subsection{Estratégia de pesquisa}

Este trabalho pode ser caracterizado como uma pesquisa documental e exploratória, em que foram feitos levantamentos de dados por meio dos regulamentos de campanhas promocionais no Natal de 2016, em dois shopping centers selecionados para a pesquisa. Utilizaram-se dois modelos de questionário como instrumentos de coleta de dados. Além disso, foram realizadas pesquisas bibliográficas sobre os temas abordados.

\subsection{Descrição da população e amostra}

Como população para estudo foram selecionadas lojas/quiosques de dois shopping centers da cidade de Ribeirão Preto (SP), a fim de verificar se o efeito free-riding ocorreu no Natal de 2016, em campanha promocional de vendas. Dessa maneira, a amostragem pode ser considerada não probabilística por conveniência, em virtude da simplicidade operacional, inacessibilidade e falta de disponibilidade de todos os respondentes da população. Lojas/quiosques participantes e não participantes de campanha promocional de vendas dos shopping centers, na época do Natal de 2016, foram objeto da investigação. Na Tabela 1, o detalhamento da população:

Tabela 1

\section{População}

\begin{tabular}{lrrrrrr}
\hline \multicolumn{1}{c}{ Shopping Center } & A & $\%$ & B & $\%$ & Amostra & $\%$ \\
\hline Participantes & 68 & $80,95 \%$ & 292 & $90,12 \%$ & 360 & $88,24 \%$ \\
Não participantes & 16 & $19 \%$ & 32 & $9,88 \%$ & 48 & $11,76 \%$ \\
Total & 84 & $100 \%$ & 324 & $100 \%$ & 408 & $100 \%$ \\
\hline Fotal
\end{tabular}

Fonte: elaborado pelos autores (2017).

Para aplicação do questionário e seleção da amostra, foram selecionados aproximadamente $25 \%$ de lojas e quiosques, em virtude das limitações para a coleta de dados e aceitação em colaborar com a pesquisa. Conforme Tabela 3, no Shopping Center A a amostra foi composta por 19 lojas/quiosques participantes e 3 não participantes da campanha promocional de vendas no período do Natal de 2016; no Shopping Center B, a amostra foi de 76 lojas/quiosques participantes e 8 não participantes. Considerando todas as lojas/quiosques dos dois shopping centers, a amostra total de participantes foi de $89,62 \%$ e a de não participantes foi de $10,38 \%$

\subsection{Procedimentos}

Pretendeu-se, no ambiente estudado: (1) identificar o agente regulador, os agentes regulados e não regulados e free-riders; (2) identificar os custos e requisitos para as lojas de shopping center participarem da campanha promocional de vendas na época do Natal; (3) analisar o regulamento da campanha promocional; (4) verificar se houve benefícios, bem como 
possíveis outros ganhos intangíveis, em função da campanha promocional para lojas/quiosques participantes e não participantes.

\subsection{Instrumento de coleta de dados}

A coleta dos dados foi realizada na segunda quinzena de janeiro de 2017, período posterior às campanhas natalinas. A fim de verificar se houve benefícios decorrentes da campanha promocional para as lojas participantes e para as não participantes, foram aplicados dois questionários assistidos ${ }^{9}$ com os gestores de lojas/quiosques que concordaram em participar da pesquisa.

Os questionários foram aplicados: (1) para lojas/quiosques participantes da promoção de Natal 2016 e (2) para lojas/quiosques não participantes da promoção de Natal 2016. Nos instrumentos de coleta de dados foram incluídas 11 questões, cuja construção se baseou no referencial teórico previamente levantado.

A primeira questão é aberta e serve para identificação do shopping center onde a loja/quiosque se encontrava. As questões de 2 a 6 são fechadas, bem como as de 8 a 10 , que são de múltipla escolha, cujos objetivos são: identificar os benefícios, bem como possíveis outros ganhos intangíveis; verificar a existência de limitações; identificar os custos e requisitos para as lojas/quiosques de shopping center participarem da regulação. A questão 7 é aberta, com o objetivo de captar o percentual (\%) de aumento de vendas relacionado ao período da campanha natalina. A questão 11 também é aberta, a fim de que o respondente acrescentasse alguma informação adicional que julgasse relevante.

\subsection{Tratamento dos dados}

Após a coleta, os dados foram agrupados e tabulados em uma planilha eletrônica, em que foi feita uma identificação e categorização das informações fornecidas pelos respondentes. Por meio de uma escala ordinal ${ }^{10}$, as respostas obtidas foram ordenadas, de acordo com 0 percentual de escolha dos respondentes.

\section{APRESENTAÇÃO E ANÁLISE DOS RESULTADOS}

A regulação tomada como objeto de investigação deste estudo é uma campanha promocional natalina destinada aos clientes dos shopping centers. Mediante o consumo de bens e serviços de acordo com as condições impostas, esses clientes ganham cupons para participação num sorteio de prêmios. Para o grupo econômico Condôminos de Shopping Center, os fatores comuns de interesse são o incentivo ao consumo no ambiente de shopping center e seu autobeneficiamento.

Primordialmente, esta pesquisa buscou obter acesso aos regulamentos das promoções da amostra, que são de dois tipos: regulamento interno (destinado a lojas/quiosques) e externo (destinado aos clientes). Destaca-se que, apesar dos esforços despendidos, somente o último (regulamento externo) foi cedido à pesquisa.

A partir dos regulamentos fornecidos e aplicação dos questionários assistidos ${ }^{11}$, analisouse a campanha promocional conforme os itens para participação de lojas/quiosques, conforme disposto na Tabela 2:

\footnotetext{
${ }^{9}$ Elaborados com base nos procedimentos propostos por esta pesquisa (apêndices A e B). O uso de dois questionários deve-se à necessidade de adaptações em determinadas questões para captar pontos de vista diferentes (participantes e não participantes). Portanto, o questionário do apêndice $A$ foi aplicado em todas as lojas/quiosques participantes da promoção de seus respectivos shopping centers; enquanto o questionário do apêndice $B$, aplicado em todas as lojas/quiosques não participantes da promoção de seus respectivos shopping centers. O questionário assistido permite ao pesquisador acompanhar e coordenar diretamente as perguntas aos respondentes, além de evitar informações incompletas.

${ }^{10}$ A escala ordinal é uma das possibilidades de mensuração dos fatos a serem pesquisados e indica a posição relativa da resposta com relação a alguma característica (Marconi \& Lakatos, 1999, p. 117).

11 Os instrumentos de pesquisa contêm informações sigilosas e, portanto, as entidades contribuintes com o estudo não serão identificadas.
} 
Tabela 2

\section{Campanhas Promocionais}

\begin{tabular}{|c|c|c|}
\hline Shopping center & A & B \\
\hline Promoção Natal 2016 & De acordo com a legislação vigente ${ }^{1}$ & De acordo com a legislação vigente ${ }^{1}$ \\
\hline Local & Ribeirão Preto - SP & Ribeirão Preto - SP \\
\hline Período & Entre 24/11 a 26/12/16 & Entre $23 / 11 / 16$ e $02 / 01 / 17$ \\
\hline Divulgação promocional & $\begin{array}{l}\text { Internet, incluindo redes sociais, site, } \\
\text { cartazes, mídias externas com outdoor, } \\
\text { flyer, assessoria de imprensa e cancelas } \\
\text { no Shopping, e talvez TV. }\end{array}$ & $\begin{array}{l}\text { Outdoor, banner, TV, rádio, internet e } \\
\text { comunicação interna. }\end{array}$ \\
\hline Pré-requisitos & Parceria com a operadora participante ${ }^{2}$ & Parceria com a operadora participante ${ }^{2}$ \\
\hline Fatores limitantes & $\begin{array}{l}\text { Lojas/quiosques que } \\
\text { exclusivamente bens e serviços não } \\
\text { contemplados }^{3}\end{array}$ & $\begin{array}{l}\text { Lojas/quiosques que } \\
\text { exclusivamente bens e transacionem } \\
\text { contemplados }^{3 ; 4}\end{array}$ \\
\hline
\end{tabular}

Nota. ${ }^{1}$ Lei o․ 5.768/71, regulamentada pelo Decreto ํ․ 70.951/72 e pela Portaria/MF ํo 41/08.

2 Permitir pagamentos das compras realizadas nos termos impostos, com os cartões participantes, nas funções crédito, débito e/ou pré-pago, transacionados, exclusivamente na máquina da operadora participante.

${ }^{3}$ Armas, munições, explosivos, fogos de artifício ou de estampido, medicamentos, bebidas alcoólicas, fumos e seus derivados; tíquetes de cinema e teatro (artigos 10 e 13 do Decreto no 70.951/72); serviços de estacionamento, bancários, câmbio e de casa lotérica.

${ }^{4}$ Tíquetes de shows do Centro de Eventos (artigos 10 e 13 do Decreto oㅜ 70.951/72); jogos eletrônicos.

Fonte: elaborado pelos autores (2017).

Os agentes da relação foram identificados em: (1) reguladores (as): Associação dos Lojistas do Fundo de Promoções do Shopping Center A e B; (2) regulados (as): lojas/quiosques participantes, isto é, que se enquadraram nos requisitos do regulamento para participação; e (3) não regulados (as): lojas/quiosques não participantes, isto é, que não se enquadraram nos requisitos do regulamento para participação ou aquelas que se enquadraram, porém optaram por não participar. A representatividade desses agentes e um indicativo da amostra de pesquisa são apresentados na Tabela 3.

Tabela 3

\section{Agentes}

\begin{tabular}{lrrrrrr}
\hline Shopping Center & $\mathrm{A}$ & $\%$ & $\mathrm{~B}$ & $\%$ & Total & $\%$ \\
\hline Reguladores (as) & 1 & - & 1 & - & 2 & - \\
Regulados (as) & 19 & $86,36 \%$ & 76 & $90,48 \%$ & 95 & $89,62 \%$ \\
Não regulados (as) & 3 & $13,64 \%$ & 8 & $9,52 \%$ & 11 & $10,38 \%$ \\
\hline Total & 22 & $100 \%$ & 84 & $100 \%$ & 106 & $100 \%$ \\
\hline
\end{tabular}

Fonte: elaborado pelos autores (2017).

É notável a existência de baixa representatividade entre os agentes não regulados da amostra em ambos os shopping centers, o que é explicado pela prévia presença de baixa representatividade dos mesmos agentes na população do estudo. Sendo assim, o cenário presente na população se transfere para a amostra. Em suma, foram poucas as lojas/quiosques que não optaram por participar da promoção de seus respectivos shopping centers.

Os principais benefícios da regulação apontados pelos agentes foram: aumento de vendas, publicidade e propaganda, e ganho de reputação, conforme apresentado na Tabela 4. 
Tabela 4

Benefícios da regulação

\begin{tabular}{|c|c|c|c|c|c|c|c|c|c|}
\hline & \multicolumn{3}{|l|}{ A } & \multicolumn{3}{|l|}{ B } & \multicolumn{3}{|c|}{ AMOSTRA TOTAL $(\mathrm{A}+\mathrm{B})$} \\
\hline & Part. & $\begin{array}{l}\text { Não } \\
\text { part. }\end{array}$ & Total & Part. & $\begin{array}{l}\text { Não } \\
\text { part. }\end{array}$ & Total & Part. & $\begin{array}{l}\text { Não } \\
\text { part. }\end{array}$ & Total \\
\hline Publicidade e propaganda & $42,11 \%$ & $66,67 \%$ & $45,45 \%$ & $56,58 \%$ & $50,00 \%$ & $55,95 \%$ & $53,68 \%$ & $54,55 \%$ & $53,77 \%$ \\
\hline Ganho de reputação & $26,32 \%$ & $66,67 \%$ & $31,82 \%$ & $21,05 \%$ & $12,50 \%$ & $20,24 \%$ & $22,11 \%$ & $27,27 \%$ & $22,64 \%$ \\
\hline Aumento de vendas & $78,95 \%$ & $66,67 \%$ & $77,27 \%$ & $90,79 \%$ & $50,00 \%$ & $86,90 \%$ & $88,42 \%$ & $54,55 \%$ & $84,91 \%$ \\
\hline Vantagem competitiva & $10,53 \%$ & $0,00 \%$ & $9,09 \%$ & $6,58 \%$ & $12,50 \%$ & $7,14 \%$ & $7,37 \%$ & $9,09 \%$ & $7,55 \%$ \\
\hline Nenhum benefício & $0,00 \%$ & $0,00 \%$ & $0,00 \%$ & $3,95 \%$ & $25,00 \%$ & $5,95 \%$ & $3,16 \%$ & $18,18 \%$ & $4,72 \%$ \\
\hline Outros benefícios ${ }^{1}$ & $10,53 \%$ & $0,00 \%$ & $9,09 \%$ & $2,63 \%$ & $0,00 \%$ & $2,38 \%$ & $4,21 \%$ & $0,00 \%$ & $3,77 \%$ \\
\hline
\end{tabular}

Todos os benefícios listados na Tabela 4 estão de acordo com as respostas dos gestores de lojas/quiosques respondentes do questionário. Os índices representam percentuais totais de lojas/quiosques que usufruíram de cada benefício - em termos de quantidade de usufruidores dentro da amostra e não em nível de captação de benefício.

Verificou-se que, dos benefícios geralmente propostos por uma regulação - subsídio, controle sobre entrada de novos concorrentes (barreira de entrada), fixação de preços, poder sobre itens substitutos e complementares (Stigler, 1971) - nenhum desses foi constatado.

A respeito do principal benefício auferido pelos agentes, observa-se na Tabela 5 que 0 percentual de aumento máximo de vendas de lojas/quiosques participantes e não participantes variou entre 70 e $200 \%$; enquanto no aumento mínimo de vendas não houve variação. O índice de $0 \%$ é persistente e ocorre em razão da descrença do aumento de vendas com a promoção de algumas lojas/quiosques.

Tabela 5

\section{Aumento em vendas}

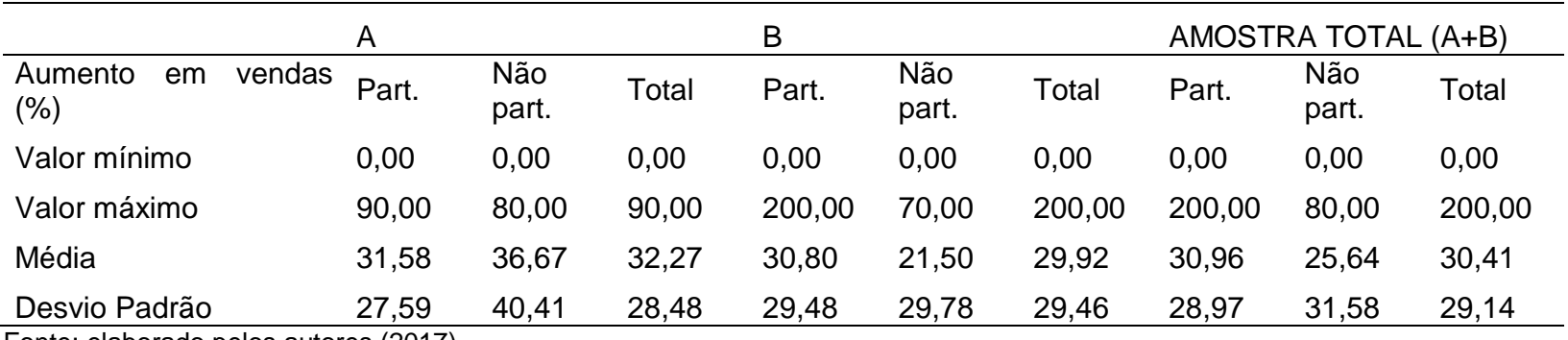

Fonte: elaborado pelos autores (2017).

Esclarece-se que o aumento de vendas é em termos de faturamento $(R \$)$, na medida de percentual (\%). Essa variável exclui o aumento de vendas natural decorrente do efeito natalino. Visto que não foi permitido acessar os dados financeiros e contábeis de lojas/quiosques, foram fornecidos valores de aumento de vendas estimados pelos gestores respondentes do questionário.

Como usual a regulações, existem custos e taxas administrativas da intervenção. Em ambos os shopping centers, esses custos estão inseridos no Fundo de Propaganda e Publicidade do Condomínio da Administradora do Shopping Center, sendo cobrados de todas as lojas/quiosques mensalmente e em dobro durante os meses de grandes campanhas (Natal e Dia das Mães), além dos encargos. Quanto à informação sobre a forma de distribuição dos custos, não foi revelada.

Posto isto, os benefícios citados foram classificados como uma mistura de bens públicos e privados por possuírem características de ambos: contribuição com custos e taxas administrativas imposta a todos pelo órgão regulador (bem público); ao mesmo tempo, exclusão de participação de alguns membros do grupo econômico (bem privado). 
Dessa maneira, como era esperado de acordo com as premissas deste estudo, os resultados indicam a existência de agentes extras na intervenção: os free-riders ${ }^{12}$, isto é, lojas/quiosques não regulados (as) que, apesar da não participação, usufruíram de um ou mais benefícios da promoção. Com isso, a Tabela 3 pode ser reapresentada da seguinte forma (Tabela 6):

Tabela 6

\begin{tabular}{lrrrrrr} 
Agentes (II) & A & $\%$ & B & $\%$ & Total & $\%$ \\
\hline Shopping Center & 1 & - & 1 & - & 2 & - \\
\hline Reguladores (as) & 19 & $86,36 \%$ & 76 & $90,48 \%$ & 95 & $89,62 \%$ \\
Regulados (as) & 3 & $13,64 \%$ & 8 & $9,52 \%$ & 11 & $10,38 \%$ \\
Não regulados (as) & 3 & $13,64 \%$ & 5 & $5,95 \%$ & 8 & $7,55 \%$ \\
Free-riders & 22 & $100 \%$ & 84 & $100 \%$ & 106 & $100 \%$ \\
\hline Total & & & & & &
\end{tabular}

Fonte: elaborado pelos autores (2017).

É pertinente destacar que nem todos os agentes não regulados foram identificados como free-riders, dado que no Shopping Center B, 3 de 8 dos agentes não regulados revelaram não ter usufruído dos benefícios. Logo, apesar de haver uma tendência racional de agir de tal modo, nem todos os agentes desejam ou obtêm sucesso em agir oportunisticamente (Albanese \& Van Fleet, 1985).

Contudo, destaca-se que, embora no Shopping Center B nem todos os agentes regulados sejam classificados como free-riders, o efeito ainda está presente. À vista disso, constata-se que o efeito carona acontece entre lojas/quiosques participantes (agentes regulados) e não participantes (não regulados) em ambos os shopping centers.

Ademais, conforme dito anteriormente, não foi possível averiguar a forma distributiva de custos e taxas administrativas da intervenção, contudo, supõe-se que foram rateados igualmente entre todos. Se verdadeira a hipótese, é possível considerar a ocorrência do efeito carona dentre os próprios participantes da regulação, dado que alguns usufruíram de maior benefício que a média despendendo a mesma contribuição.

\section{CONCLUSÕES}

Sob a luz da Teoria Econômica da Regulação e demais princípios e proposições relacionados à literatura apresentada, o objetivo deste estudo foi entender o modelo de regulação e seus impactos, detectando a existência ou ausência de efeito free-riding num ambiente de shopping center no período do Natal de 2016, em campanha promocional de vendas. $\mathrm{O}$ freeriding pode desfavorecer o bem-estar comum do grupo econômico, o que pode ser caracterizado como um problema e levar à busca de soluções, coercivas ou empreendedoras.

Esta pesquisa utilizou como proxy do efeito carona o usufruto dos benefícios provenientes da campanha promocional por lojas e quiosques não inseridos no regulamento. Além disso, outros elementos presentes no regulamento e no questionário aplicado por meio de entrevista foram considerados neste estudo.

Por meio dos resultados, constatou-se que de fato há o efeito carona no ambiente de shopping center no Natal de 2016, em campanha promocional de vendas, entre lojas/quiosques participantes e não participantes da regulação. Ainda que a regulação vise estabelecer uma barreira de entrada para não membros do grupo de interesse, por vezes isso não é completamente possível e, então, aparecem os free-riders. Ou seja, foi possível constatar evidências do uso dos benefícios da regulação por lojas/quiosques não participantes da regulação. Portanto, conclui-se que o free-riding pode ocorrer num ambiente de shopping center, em campanha promocional de vendas no período natalino.

\footnotetext{
${ }^{12}$ O termo mais apurado à condição é "cheap rider" (“caroneiro barato") (Stigler, 1974) - visto que sua carona não é puramente grátis, pois houve a contribuição compulsória de todos com os custos. Todavia, free-rider, o termo mais comum, será adotado ao caso (Albanese \& Van Fleet, 1985).
} 
Quanto ao efeito entre as próprias lojas/quiosques participantes, não é possível afirmar com certeza sua ocorrência. O desconhecimento da forma de rateio dos custos da intervenção e a falta de acesso a outras informações dificultam a averiguação. Entretanto, seguindo a hipótese de uma mesma contribuição para todos, considera-se provável a existência do efeito estudado.

Os impactos do free-riding são identificados como motivadores ou desmotivadores para participação da regulação em questão, em decorrência dos incentivos e desincentivos para caronar (Albanese \& Van Fleet, 1985), além de interferir negativamente no bem-estar comum do grupo.

Embora os custos sejam de pagamento compulsório, algumas lojas/quiosques optaram pela não participação apesar de se enquadrarem nas normas. Dentre os motivos foram apontados: não consentimento da empresa matriz (central decisora), perda do prazo para adesão à regulação e desinteresse por ausência de benefício aparente.

Ademais, verificou-se desconhecimento do conceito consolidado do free-rider por parte da maioria dos respondentes, apresentando uma forma mais "inconsciente" ou "superficial", embora popular. Havendo o problema do free-rider, isso dificulta a busca por soluções, em especial as empreendedoras, haja vista que os membros do grupo são os melhores para propôlas (O’Neill, 2010).

Contudo, o que ocorre em ambos os shopping centers é que a solução proposta é coerciva, isto é, o pagamento dos custos da intervenção é compulsório, imposto pelos órgãos reguladores. Aparentemente esse arranjo não alcança o ponto máximo do bem-estar comum do grupo, visto que nem todos podem usufruir do benefício, e o efeito continua a acontecer.

Portanto, a fim de minimizar a assimetria estimuladora do free-riding, sugere-se a exploração de uma solução empreendedora elaborada em conjunto pelo grupo econômico, sendo interessante a participação dos órgãos reguladores.

É válido lembrar que, somada à dificuldade de encontrar o arranjo solucionador do problema, em concordância com Stigler (1971), há ainda uma complexidade mais primordial da regulação: descobrir quando e por que um grupo é capaz de usar o órgão regulador para os seus próprios fins, ou é apontado pelo agente regulador a ser utilizado para fins alheios. Logo, a questão não é tão simples quanto parece.

Além disso, o estudo admite que certas limitações devem ser levadas em consideração, tais como: o tamanho da amostra, o número de eventos e período utilizados, ou seja, amostra, eventos e períodos relativamente pequenos quando comparados com o total. Essa restrição se deve em parte à complexidade de obter informações tidas como confidenciais das entidades envolvidas. Adicionalmente, as variáveis apresentam aspectos intangíveis e de delicada mensuração, o que dificulta a análise de modo geral. Outra limitação é a escassez de estudos sobre o assunto, bem como de pesquisas com aplicação da Teoria Econômica da Regulação sob perspectivas diferentes das áreas de Política e Poder Público.

Fiani (2004, p. 81) também revela dificuldades quanto ao assunto:

Os modelos mais relevantes da teoria econômica da regulação são revistos criticamente neste trabalho, sendo apontadas as inconsistências entre os resultados teóricos e a falta de suporte empírico de caráter decisivo para esses modelos, apontando-se a necessidade de se considerar a autonomia do regulador perante os grupos de interesse e o contexto institucional.

Para futuras pesquisas, sugere-se ampliação do tamanho da amostra, do número de eventos e período utilizados, bem como a aplicação de outra metodologia para que se comparem resultados. Assim como a proposta deste trabalho, outros poderão abordar demais áreas a fim de extrapolar a aplicação da teoria econômica da regulação, fundamentalmente voltada para a intervenção do Estado na economia, no intuito de melhor compreender a dinâmica do efeito carona e outros assuntos em cenários mais específicos. 


\section{REFERÊNCIAS}

Albanese, R. \& Van Fleet, D. D. (1985). Rational behavior in groups: The freeriding tendency. The Academy of Management Review, 10(2), 244-255.

Bakos, Y. (2001). The emerging landscape for retail e-commerce. Journal of Economic Perspectives, 15(1), 69-80.

Buchanan, J. M. (1965). Ethical rules expected values, and large numbers. Ethics, 76, 1-13.

Carlton, D. W. \& Chevalier, J. A. (2001). Free riding and sales strategies for the Internet. The Journal of Industrial Economics, 49(4), 441-461.

Castro, L. T., Neves, M. F., \& Scare, R. F. (2015). Eficiência de representação das associações de produtores de cana-de-açúcar no Brasil. Organizações Rurais \& Agroindustriais, 17(3), 383-397.

Ceribeli, H. B. \& Conte, G. M. (2016). Análise do comportamento caronista no comércio eletrônico. Nucleus, 13(1).

Comitê de Pronunciamentos Contábeis (2016). Conheça o CPC. Recuperado em 20 setembro, 2016, de http://www.cpc.org.br/CPC/CPC/Conheca-CPC

Departamento Estadual de Trânsito de São Paulo (2016). Fale conosco. Recuperado em 09 setembro, 2016, de https://www.detran.sp.gov.br/wps/portal/portaldetran/detran/atendi mento/faleconosco

Dias, S. W. (2014). O desafio do varejo multicanal: comportamento free-riding do consumidor. Tese de Doutorado em Ciências, Faculdade de Economia, Administração e Contabilidade, Universidade de São Paulo, São Paulo, Brasil.

Downs, A. (1999). Uma teoria econômica da democracia. São Paulo: Edusp.

Farhat, S. (2007). Lobby. O que é. Como se faz: ética e transparência na representação junto a governos. São Paulo: Peirópolis.

Fiani, R. (2004). Afinal, a quais interesses serve a regulação? Campinas: Economia e Sociedade, 13(2), 81-105.

Friedman, M. (1975). There's No Such Thing As a Free Lunch. Open Court.

Gremaud, A. P. (2003). Manual de Economia. Organizadores: Diva Benevides Pinho e Marcos Antônio Sandoval de Vasconcellos (4a ed.). São Paulo: Saraiva.

Jensen, M. C. \& Meckling, W. H. (1976). Theory of the firm: managerial behavior, agency costs and ownership structure. Journal of Financial Economics.

Leite, J. R. M. (2010). CNPI, CFA, CEl: saiba mais sobre os certificados para profissionais do mercado. Recuperado em 31 agosto, 2016, de http://www.infomoney.com.br/mercados/noticia/1769087/cnpi-c/fa-cei-saiba-mais-sobrecertificados-para-profissionais-mercado

Mankiw, N. G. (2006). Introdução à Economia (3a ed.). São Paulo: Thomson Learning.

Marconi, M. A. \& Lakatos, E. M. Técnicas de pesquisa. São Paulo: Atlas, 1999. 
Mckenzie, R. B. \& Tullock, G. (1978). Modern political economy: An introduction to economics. New York: McGraw-Hill.

Moreno, A. C. (2014). Veja como tirar o certificado de proficiência em inglês. Recuperado em 31 agosto, 2016, de http://g1.globo.com/educacao/noticia/2012/07/veja-como-tirar-ocertificado-de-proficiencia-em-ingles.html

O'Neill, B. (2010). Resolvendo o "problema" do carona. Recuperado em 20 maio, 2016, de http://www.mises.org.br/Article.aspx?id=724

Olson, M. (1965). The logic of collective action: Public goods and the theory of groups. Cambridge, MA: Harvard University Press.

Shin, J. (2007). How Does Free Riding on Customer Service Affect Competition? Marketing Science, 26(4), 488-503.

Silva, A. D. \& Brito, E. P. Z. (2013). Incerteza, racionalidade limitada e comportamento oportunista: um estudo na indústria brasileira. RAM, Revista de Administração Mackenzie, 14(1), 176-201.

Simonsen, M. H. \& Cysne, R. P. (2009). Macroeconomia (4a ed.). São Paulo: Atlas.

Slack, N., Chambers, S., \& Johnston, R. (2002). Administração da produção (2a ed.). São Paulo: Atlas.

Spahn, S. (2013). Cross-channel free-riding consumer behavior in a multichannel environment: An investigation of shopping motives, sociodemographics and product categories. Journal of Retailing and Consumer Services, 20(6), 570-578.

Stigler, G. J. (1971). The Theory of Economic Regulation. The Bell Journal of Economics and Management Science, 2(1), 3-21.

Stigler, G. J. (1974). Free Riders and Collective Action: An Appendix to Theories of Economic Regulation. The Bell Journal of Economics and Management Science, 5(2), 359-365.

Stroebe, W. \& Frey, B. S. (1982). Self-interest and collective action: The economics and psychology of public goods. British Journal of Social Psychology, 21, 121-137.

Tullock, G., Seldon, A., \& Gordon, L. B. (2002). Government failure: a primer in public choice. Catho Institute, Washigton D. C.

Van Baal, S. \& Dach, C. (2005). Free-riding and customer retention across retailer's channels. Journal of Interactive Marketing, 19, 75-85. 


\section{APÊNDICE A - Modelo de Questionário: Lojas/quiosques Participantes}

Participantes da promoção de Natal 2016

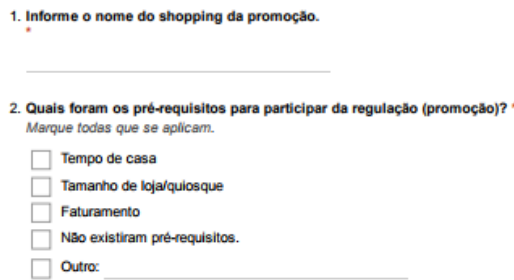

3. Existiu alguma fator limitante as lojas/quiosques para participar? *

Merque todas que se spicican.

Ser estabelecimento do propio shopping

Ser estabelecimento estritamente de serviços

NBo existiram fatores limitantes.

$\square$ Outro:

4. Houve algum custo ou taxa administrativa para participaç̧o?

Marcar apenas uma oval.

O(s) premmio(s) e demals custos foram rateasdos (dvididios) entre os paricicipantes.

Os custos ja estavam inclusos no valior de locaçao do estabelecimento

Somente uma taxa administrativa

Nenhum custo.

Outro:

5. Dos beneficios geralmente propostos por uma regulaçă (promoçao), quais foram
oferecidos? Merecidos?"

$\square$ subsidio

Controle sobre entrada de novos concorrentes (bameira de entrada)

] Fixaça de preços

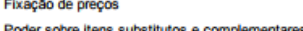

Nenhuma das altemativas anteriores.

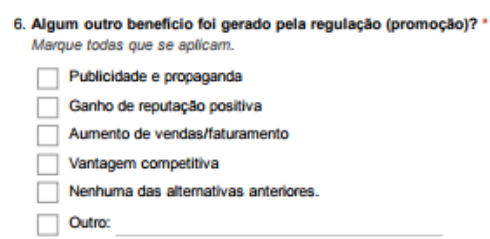

9. Acredita que existiu efeito carona (tree-riding) na regulaçăo em queståo?

Segundo Albanase e Van Fleet (1985), o efeito tree-riding - ou efeito carona - é definido como a

atuaç̧o em que um membro de um grupo obtém benefficios da membresia do grupo, porém nấ suporta um compartilhamento proporcional dos custos de prover talis beneficicios.

Sim, dentre os participantes.

Sim, entre participantes e nå participantes.

Todas as altemativas anteriores.

Nenhuma das alternativas. Naso houve efeito carona (free-riding).

10. Como participante, por qual(is) motivo(s) participou da promoçà? Marque todas que se aplicam.

7 Baixo ou nenhum custo

Especial aumento de vendas

Outros beneficios tangiveis e intangivei

Ausência de efeito carona (free-riding)

$\square$ Outro:

11. Se deseja fornecer alguma intormaçăo

\section{APÊNDICE B - Modelo de Questionário: Lojas/quiosques Não Participantes}

Não participantes da promoção de Natal 2016

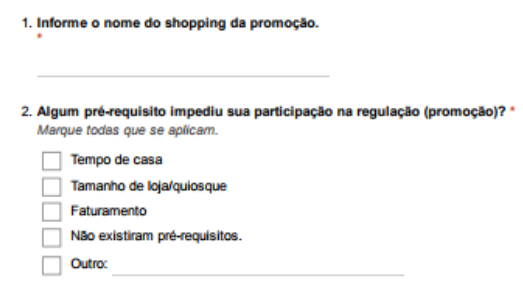

3. Existiu alguma outro fator limitante para sua participaç̧o? *

Merque todas que se apican.

1] Ser estabelecimento do proprio shopping

$\square$ Ser estabelecimento estritamente de serviços

7 NBo existitram tatores limithantes.

$\square$ Outro:

4avia algum custo ou taxa administrativa para participaç̧o?

Marcar apenas uma ovel.

O(s) premio(s) da promoçao e demais custos foram rateados (divididos) entre os

Os custos ja estavam inclusos no valor de loccaçao usualis do espaço do

Somente uma taxa administrativa.

Nenhum custo

Outro:

5. Dos beneficios geralmente propostos por uma regulaçä (promoçäo), quais foram
fferecidos?

"oferecidos?

$\square$ Subsidio

Controle sobre entrada de novos concorrentes (harretra de entrada)

$\square$ Fixeçăo de preços

Poder sobre itens substitutos e complementares

Nenhuma das sthemativas anteriores.

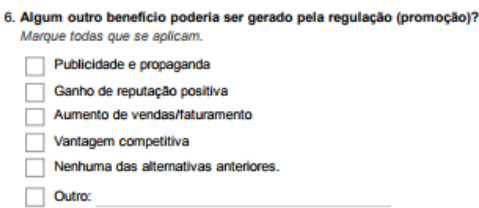

7. Acredita que a regulaçào gerou quantos \% de ganhos adicionais?

Responda a pergunta isolando-se o aumento de vendassffaturamento natural devido ao periodo

Marcar apenas uma oval.

$\bigcirc \ldots . . . . . . . . . \%$

8. Acredita que a promoçă beneficia a:

Marcar apenas uma oval

Somente lojas/quiosques participantes

Somente lopstoviosques NĀO participantes

Todas as logas/quiosques (participantes en nao participantes)

Nenhuma das lopas/quiosques (participantes e nåo participantes)

Outro:

Acredita que existiu efeito carona (free-riding) na regulaçá em questao?

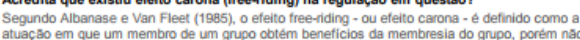

grupo obtém beneficicos da membresia do grupo, porém n

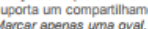

Sim, dentre os participantes.

sim, entre paricipantes e nao parricipantes.

Todas as attemativas anteriores.

Nenhuma das allemativas. NBso houve efeito carona (free-niding.

10. Como nåo participante, por qual(is) motivo(s) nåo partícipou da promoçăo?

Custos

Pouco ou nenhum beneficic

Nao cumprimento dos pre-requisitos etou restriçces (tatores limitantes) para participoseco

6 Efetto carona (free-niding)

Outro:

11. Se deseja tornecer alguma intormaça 